\title{
Measurement of Mechanical Strength of Glass-to-Metal Joints
}

\author{
A. Selçuk* and A. Atkinson \\ Department of Materials \\ Imperial College \\ London SW7 2BP, UK
}

* Present address: Ceres Power, Viking House, Foundry Lane, Horsham, RH13 5PX UK

\begin{abstract}
Three different test geometries were used to apply shear loading to fracture glass-to-metal joints typical of seals intended for use in planar solid oxide fuel cells: asymmetric compression; symmetric compression; and four-point asymmetric bending.

The measured apparent shear strengths were found to differ by an order of magnitude depending on the test configuration employed. In particular, the apparent shear strength measured in the asymmetric compression test was very low. Conversely, the highest apparent shear strengths were measured using the symmetric compression test and the four-point asymmetric bend test gave an intermediate result. It is shown by finite element modelling that these differences are caused by differences in the normal stresses transverse to the joint. The locus of failure was always along the glass/metal interface in all test geometries.
\end{abstract}

It is concluded that mechanical test procedures used to characterise glass-ceramic seals in SOFC stacks need to be selected and interpreted with great care.

Keywords:

Solid oxide fuel cell, seal, testing, glass, strength 


\section{$1 \quad$ Introduction}

Interfaces between metals and brittle materials, such as ceramic or glass, are encountered in a wide variety of situations in which their mechanical properties are important. These include composites, coatings, and structural joints. Joints in the form of a layer between two metal surfaces are used as electrically insulating, gas-tight high temperature seals in solid oxide fuel cells [1]. The seal materials are often of glass, glass-ceramic or glass and ceramic $[2,3,4,5,6,7,8,9,10]$. Since these composite joints have a brittle adhesive layer, the mechanical properties of the joints are crucial for the reliability of the fuel cell stack and suitable test methods are required to assess their mechanical performance $[11,12,13,14]$. Such a test method should reflect, as closely as possible, the stress state expected in the actual application.

The stresses experienced by these joints are the summation of residual stresses and applied operational stresses. The residual stresses arise mainly from differences in thermal expansion between the adhesive material and the adherends being joined when the operating (or testing) temperature is different from the effective temperature at which the seal was fabricated in a stress-free state. For a glass adhesive the effective fabrication temperature is approximately its glass transition temperature, since above this temperature the glass is sufficiently fluid to allow stresses to be relaxed. In planar fuel cell concepts the residual stresses are predominantly in-plane biaxial stresses and they are concentrated in the material having the smallest thickness, which is usually the adhesive layer. The residual stresses are in-plane biaxial in the bulk of the seal at distances greater than a few times the seal thickness from the seal edges. However, closer to the seal edges the free surfaces at the edges convert the residual stresses into shear stresses of similar magnitude to the bulk biaxial stresses.

The applied operational stresses can be very complicated and sensitive to the details of the stack and cell design. They are also usually mainly thermally generated, either by differences in thermal expansion coefficients or by spatial variations in temperature. In planar fuel cells these stresses tend to be biaxial shear stresses, but can be very different in specific designs and locations. For example, Blum et al. [15] carried out a detailed combined thermal and stress analysis of a planar stack and found large tensile stresses of the order of $40 \mathrm{MPa}$ were generated in the seal material near the gas manifolds. Nevertheless, a desirable feature of any 
method for characterising the mechanical strength of glass-to-metal joints is that the applied loading should be predominantly in shear. In addition, the plates of the fuel cell stack are usually horizontal so that any given plate supports the weight of the plates on top of it. The joints thus experience an out-of plane compressive stress and thus test methods that involve out-of plane tensile stresses are not suitable.

The objective of the research described here was to evaluate some possible experimental methods for measuring the apparent shear strength of glass-to-metal joints; particularly those for use in solid oxide fuel cells.

\section{$2 \quad$ Selection of test methods}

Glass-to-metal joints have many features in common with other types of adhesive joint and therefore selection of a test method can be guided by the knowledge established in the field of adhesive strength measurement. Many of these tests have been applied to measure the strength of metal/oxide interfaces [16,17,18], but they usually apply a tensile load perpendicular to the bonded interface (i.e. opening mode, or mode I loading). A simple test in which the loading is applied in shear (mode II) is the single lap tensile shear test [19]. However, although the load is applied in shear, there are severe tensile opening mode stresses induced near the ends of the joint. Therefore it is necessary to use a test configuration that does not induce unintended tensile stresses. Ventrella et al. [20] and Ferraris et al. [21] have explored a number of shear test configurations for ceramics bonded by epoxy adhesives and draw attention to the difficulty of achieving reliable results. For example they report that for ceramic/epoxy joints the lowest mean apparent shear strength was $29 \mathrm{MPa}$ measured using a double offset lap joint loaded in compression and the highest was $54 \mathrm{MPa}$ measured using a circular butt joint loaded in torsion. Furthermore the testing method also had a large influence on the Weibull modulus of the strength distribution; being lowest for the double offset lap joints and highest for single offset lap joints also loaded in compression.

In this study we have examined three test configurations (Figure 1) applied to two SOFC seals: an asymmetric (offset) compressive single lap joint, a symmetric compressive single lap joint and a four-point shear-loaded butt joint. The tests were chosen based on ease of specimen manufacture and application of load. One seal type was a single layer of glass, and the second was a triple layer with the configuration glass/spinel/glass. The approach adopted in each case was first to analyse the applied stress distribution by finite element modelling 
(FEM) using the ABAQUS code. The FEM results were then used to refine the loading configuration in order to optimise the applied stress distribution from the point of view of uniformity of the shear stress. Finally, the optimised configuration was applied to some typical joints and the experimental observations analysed and compared.

Amara et al. [22] devised a single lap asymmetric compression shear test (based on an existing standard test for adhesive joints between wood components [23]) suitable for brittle adherends which they applied to alumina and silicon carbide ceramics bonded by epoxy adhesives. We have investigated a similar test applied to glass-to-metal joints.

The general arrangement of the test is shown in Figure 1a. The compressive load, $P$, is applied to one of the offset ends of the asymmetrical lap joint. In order to prevent the specimen rotating under the applied load, the specimen is restrained by clamping the bottom adherend and applying a horizontal force to the top adherend by means of a rigid restraint. The details of the clamping arrangement and the height at which the horizontal restraint is applied are critical parameters in controlling the stress distribution in the joint. Using FEM, Amara et al. were able to optimise their test geometry to give almost a symmetrical distribution of shear and normal stresses in the bond material. In their optimised configuration the computed shear stress varied by $\pm 5 \%$ within the adhesive and the maximum transverse normal stress was compressive and approximately equal to the mean shear stress. We followed a similar procedure to optimise the position of the upper restraint when applied to our specimens. The optimised test dimensions are shown in Figure 1a and the corresponding FEM stress distribution for the optimised configuration is shown in Figure 2. The material parameters used in the FEM are given in Table 1. In agreement with Amara et al. the shear stress is fairly uniform away from the ends and there is a large transverse compressive stress of a similar order of magnitude to the average shear stress. The FEM analysis also shows that the maximum shear stress for this configuration is approximately $20 \%$ greater than the average shear stress. It should be noted that the stresses discussed in this paper only refer to the stresses originating from the external loading and do not include the residual stresses in the joint material. The residual stresses at room temperature can be estimated from the material parameters given in Table 1 and assuming that the stress-free temperature is the glass transition temperature of the glass $\left(660^{\circ} \mathrm{C}\right)$. The result is that there is likely to be a high residual compressive biaxial stress of approximately $200 \mathrm{MPa}$ in both the glass and the spinel in the plane of the joint and away from the edges of the joint plus the shear stresses near the 
edges of the joint. The effect of these residual stresses on the apparent strength of the joint is not evaluated explicitly here. This is because they will only contribute to crack propagation if they are substantially relaxed during the fracture. If the sealant remains adherent to one of the adherends after fracture then the residual stresses will remain substantially unrelaxed and will not contribute to long range crack extension. However, the large shear stresses at the edges of the joint, although of short range, could be capable of generating defects that are initiating sites for failure under the applied stresses. This situation has been analysed in detail using a fracture mechanics approach and indicates that the residual stresses can produce edge cracks of length similar to the joint thickness which can then acts as defects that can initiate fracture under the action of the applied stresses [24]. As a result, the effects of the residual stresses are here considered as part of the properties of the joint system and failure is characterised only by the applied stresses.

In the course of the experiments using the asymmetric compression configuration (see later) it was found difficult to ensure a sufficiently rigid upper restraint and therefore a symmetric compression test arrangement was investigated (Figure 1b). In this configuration, the symmetry of the lateral restraints ensures that the stress distribution is not sensitive to their rigidity. All the supports have circular cross-section so that the bonded assembly can rotate reasonably freely in response to the applied load. FEM analysis was again used to optimise the location of the lateral supports in order to obtain as uniform as possible shear stress over the bonded area. The FEM analysis of the optimised arrangement is shown in Figure 3 assuming rigid frictionless support rollers. In this example the shear stress is not as uniform as in Figure 2, because there is more rotation of the specimen in the anticlockwise direction in Figure $1 \mathrm{~b}$, and the maximum shear stress is approximately $50 \%$ greater than the average shear stress. Again there are large parasitic compressive normal transverse stresses induced in the joint.

In order to reduce the normal stresses, a four-point asymmetric bending test (Figure 1c) using a butt joint was also investigated. This is based on an arrangement proposed by Ünal et al. [25], and subsequently adopted as ASTM C1469-00, and gives a state of almost pure shear in a narrow joint, provided that the inner loading points are close to the joint. However, the shear stress is not uniform; it is zero at the upper and lower edges and reaches a maximum at the mid-point. The maximum shear stress is given analytically by 


$$
s_{12, \text { max }}=\frac{P}{A} \frac{3(a-b)}{2(a+b)}
$$

where $P$ is the applied load, $A$ is the area of the joint, $a$ is the distance between the outer loading points and $b$ the distance between the inner loading points.

Pickard et al [26] have suggested a modification of the asymmetric (offset) lap compression test in which the applied load does not exert a bending moment and thereby removes the need for lateral restraints. Their FEM analysis showed that in the optimised geometry the normal stresses are close to zero over most of the joint, but are significantly compressive (approximately equal to the shear stress) close to the edge of the joint. The specimen for this test is produced by cutting two displaced notches through the joint; one through each adherend. In the case of brittle adhesive bonding materials, this operation is likely to cause significant damage to the joint at the place where failure is likely to be initiated and could therefore give rise to unrepresentative low apparent strengths with glass bonded joints.

\section{Experiments}

\subsection{Specimen preparation}

The specimens were representative of ones used as seals in some planar solid oxide fuel cell concepts [1]. The adherends were fabricated from $\mathrm{Cr} 5 \mathrm{Fe} 0.2 \mathrm{Y}_{2} \mathrm{O}_{3}$ alloy (CFY, Plansee, Austria) and the adhesive bond was one of two types. The first was a single layer of glass

adhesive (AF 45, Deutsche Spezialglas AG, Germany) with a thickness of $150 \mu \mathrm{m}$. The second consisted of three layers in which a $600 \mu \mathrm{m}$ thick layer of $\mathrm{MgAl}_{2} \mathrm{O}_{4}$ spinel was sandwiched between two layers of a $180 \mu \mathrm{m}$ thick AF45 glass. The purpose of the spinel mid-layer in the triple layer bond is to reduce the transverse ionic conductivity of the joint for SOFC application at a relatively high operating temperature (e.g. $900^{\circ} \mathrm{C}$ ). The faces to be bonded of the metal adherends were ground flat to a $25 \mu \mathrm{m} \mathrm{SiC}$ finish and then cleaned in acetone. The glass and spinel were provided in the form of sheets which were then used to fabricate the joints using ceramic jigs to hold the components in place and to control the dimensions of the bond layer. The bonds were formed by heating in the jigs to $900^{\circ} \mathrm{C}$ to soften the glass and then cooled to room temperature at a rate of $2^{\circ} \mathrm{C}$ per minute.

A scanning electron micrograph (SEM) of the edge part of a typical joint is shown in Figure 4. 


\section{2 Strength measurements}

The schematic of the apparatus used for the asymmetric compression test is shown in Figure 5. The upper restraint was a rolling bar housed in lubricated ball joints at both ends to minimise friction. The base was built to enable the height of the upper restraint to be adjusted in order to achieve symmetrical distribution of stresses in the joints. The horizontal movement of the upper restraint was spring-loaded to ensure that the initial contact, when the specimen was not vertically loaded, was consistent from specimen to specimen. The upper restraint was then locked in place before applying the vertical load to try and prevent horizontal displacement at this point during subsequent loading. Note that after locking the spring does not provide the horizontal restraining force. If the upper restraint is infinitely stiff then the restraint automatically supplies the force required to prevent displacement. However, in reality this arrangement was not sufficient to prevent such a displacement completely. A linear displacement transducer was used to monitor the rigidity of the restraint during loading.

A schematic of the apparatus used for the symmetric compression test is shown in Figure 6. The specimen was supported by the rolling bars and the vertical load was applied through the same loading cap as used for the asymmetric lap-joint tests. Support blocks were introduced between the specimen and the rolling bars in order to avoid contact stresses that would alter the stress distribution within the joint section. Indeed, the FEM analysis of the stress distribution in the joint section indicated that the contact stresses, which develop in the absence of the support blocks, alter the stress distribution in the joint section, considerably. This effect was found to diminish when the support blocks were applied.

In both symmetric and asymmetric tests, the vertical load was applied in a standard mechanical testing machine through a cap with a spherical head to ensure vertical transmission of the load. A cross-head speed of $2 \mathrm{~mm}$ per minute was applied until the failure of specimens. The apparent shear strength was determined from the failure load divided by the planar area of the bonded region.

The test configuration for the four-point shear-loaded butt joint is illustrated in Figure 7. The asymmetrical arrangement of the four rolling bars provided two force couples acting opposite to each other, the inner one being anticlockwise and the outer one being clockwise. The fifth rolling bar located at the top of the loading block was used to apply the load concentrically. Before loading, it was ensured that the centre-line of the rolling bar for loading was aligned 
with the centre of the joint section and the edge of the joint section was aligned parallel to the symmetry lines of the rolling bars (Figure 7). The load was applied at a cross-head speed of 2 $\mathrm{mm} /$ minute and the maximum shear stress was calculated according to Equation 1.

In the three test rigs, the rolling bars and the main load bearing components were made of hardenable steel. Thus the contact surfaces were hardened by heat treatment in order to avoid locking of the rolling bars in contact regions during loading.

The triple layer bond was tested in the asymmetric and symmetric compression tests and the single layer bond in the symmetric compression and the 4-point bend tests. Approximately 15 specimens were tested for a given combination of bond type and test geometry.

\section{$4 \quad$ Results and discussion}

\subsection{Asymmetric compression test}

The apparent shear strengths (defined as the load at fracture divided by the area of the bonded region) of the triple layer bonded joints tested in this configuration are shown in the form of a Weibull plot in Figure 8 and the parameters of the distribution are summarised in Table 2. Although the maximum shear stress for this configuration is obtainable from the FEM analysis, we choose to present the strength as the average (or apparent) shear stress in view of the transverse stresses that depend on the rigidity of the lateral support as discussed below. The mean apparent strength and Weibull modulus are both low, the latter indicating considerable variability in the fracture initiation process. The fracture path was along the glass/metal interface furthest away from the upper adherend to which the load was applied. The fracture appeared to have initiated in the region of the upper edge and the crack travelled from there down the interface although the sites of fracture initiation could not be clearly identified from inspection of the fractured surfaces. Crack deviation from the adherend/adhesive interface has been reported for silicon carbide adherends and epoxy adhesive in the asymmetric compression test [10]. We did not observe any crack deviation in our specimens in this test. This could be due to several factors, such as: different elastic constants; different ratio of cohesive and adhesive fracture energies, or; lower strain to failure and higher stiffness in the glass bond which exacerbates the effects of the parasitic tensile stresses. However, crack deviation was invariably found for our joints in the symmetric compression test (see below). These issues are discussed later. 
Figure 9 shows the apparent shear strength (expressed as the load at fracture) of each specimen plotted as a function of the lateral displacement of the upper restraint measured for that specimen at the failure load. The plot shows a strong inverse correlation between the two parameters in that the higher the apparent strength of the specimen the smaller the lateral displacement. A similar conclusion was drawn by Ferraris et al. [21] who reported that lower apparent strength of epoxy bonded composites in a range of different tests was correlated with the maximum out of plane normal stress calculated using FEM. An example of the stress distribution across a three-layered joint when the upper restraint has displaced by $10 \mu \mathrm{m}$ is shown in Figure 10. The stresses are plotted across the joint at a position $60 \mu \mathrm{m}$ below the top edge of the joint. This is close to the top, but not at the top, because at the top the sharp corner where the glass meets the metal leads to unrealistically high stress artefacts. The example in Figure 10 shows that the displacement in the upper restraint induces a large tensile stress $\left(s_{11}\right)$ at the interface between the glass and the metal on the opposite side to the restraint and is approximately four times the shear stress $\left(s_{12}\right)$ at the same location. Thus the FEM study revealed that although the lateral displacements are small, they are sufficient to induce high parasitic tensile stresses in the region where the failure initiated. Consequently, in this test configuration there is a mixture of shear and a largely uncontrolled parasitic normal tensile stress which is very sensitive to the rigidity of the upper restraint. Experimentally this varies from specimen to specimen and is determined by the variability in setting up the restraint as well as its compliance. These effects not only lower the mean apparent strength of the joint, but also could increase the variability and lower the apparent Weibull modulus of the joint strength.

\subsection{Symmetric compression test}

The apparent shear strengths of the triple layer bonded joints tested in this configuration are shown in the form of a Weibull plot in Figure 11 and the parameters of the Weibull distribution are given in Table 2. As with the asymmetric test results, we choose to present the results as apparent shear strength because of the large influence of the transverse stresses. The apparent strength of the triple joint measured in this configuration is approximately one order of magnitude greater than measured for the same type of joint in the asymmetric configuration. The FEM analysis shows that this is because the normal transverse stresses remain large and compressive in the symmetrical configuration because of the specimen rotation. Thus, not only is the opening mode contribution to crack initiation and propagation 
absent, but the compressive stresses will create frictional forces in the crack wake that will shield the crack tip from the applied load and be reflected in higher apparent strength.

The variability in apparent shear strength, as reflected in the Weibull modulus, is not significantly different from that determined in the asymmetric test. This probably indicates that there is a wide spectrum of defect sizes from which the fracture is initiated, but the variability in the transverse stresses obscures this to some degree.

The apparent shear strengths of the single layer bonded joints tested in this configuration are also shown in Figure 11 and the parameters of the distribution are summarised in Table 2. The apparent strength of the single layer joint is slightly lower than the triple layer joint, but the Weibull moduli are approximately equal.

The fracture paths observed for both types of joint tested in the symmetric configuration were essentially along the glass/metal interface. The fractures initiated at the seal edge opposite the laterally restraining rollers (that is, at the edge location where the compressive stress was lowest), travelled along the glass/metal interface and then deviated across the joint, approximately half way along the interface, to cross to the opposite interface and finally extend along that interface to complete separation.

The surface profile of the separated members in the neighbourhood of the deflecting crack was determined using a Talysurf stylus profilometer and typical results are shown in Figure 12. The crack deviation angle (as it leaves the first interface and enters the glass layer) was measured to be $15^{\circ} \pm 2^{\circ}$ for single layer joints and $18^{\circ} \pm 1^{\circ}$ for triple layer joints. The crack was found to deviate further as it enters into the spinel layer in the triple layer joints, reaching a value of $34^{\circ} \pm 2^{\circ}$. These values can be compared with crack deviation reported for silicon carbide/epoxy joints in the asymmetric compression test for which the crack deviation angle was found to be $57^{\circ} \pm 3^{\circ}$ and the location of the deviation point was random [10]. This difference in behaviour is caused by the higher modulus and lower fracture energy of the glass and ceramic joint materials in comparison with the epoxy. Evans et al. [27] have discussed the conditions for cracks to deviate from the interface in adhesive failure tests and emphasise the role of the loading phase angle, $\Psi$, in deflecting the crack from the interface into the brittle material. They conclude that the probability of crack deflection is greatest when the loading phase angle is approximately $70^{\circ}$. The phase angle is approximately given by 


$$
\Psi \approx \tan ^{-1}\left(\frac{v}{u}\right)
$$

where $v$ is the shear displacement and $u$ is the opening displacement of the crack faces. The transverse compressive stress in this test configuration will suppress any opening displacement until approximately midway along the joint where the transverse compression is smallest (Figure 3). The situation for the asymmetric lap joint is different because the transverse stress becomes tensile as a result of insufficient rigidity in the upper restraint leading to a low value of $\Psi$ and opening mode loading.

\subsection{4-point asymmetric bend test}

The results for the 4-point bend test on the single layer joints are shown in Figure 11 and summarised in Table 2. The strength parameter given is the maximum shear stress at the interface at failure as calculated from Equation 1. The mean shear strength measured in this test was approximately half that measured for the same type of joint in the symmetric compression test, which reflects the absence of compressive normal stresses in the 4-point configuration. However, the difference is not as large as observed with the asymmetric compression test because there are no large normal tensile stresses in the 4-point configuration. The Weibull modulus is again small, indicating a similar level of variability in fracture-initiating defects. This also implies that the Weibull modulus in the two lap joint tests is dominated by the variability in defects within the joint and not be the variability in the transverse stresses. However, in the 4-point configuration the shear stress goes to zero at the free edges and therefore the fracture is not initiated from edge defects in this test. The fracture of the joints produced flat surfaces at one of the two metal-to-glass interfaces without preference. Thus the low Weibull modulus suggests that a population of defects exists throughout these interfaces similar to those present at the edges.

The mean apparent shear strengths in Table 2 span a wide range (from 7.3 to $83 \mathrm{MPa}$ ). Malzbender and Zhao [28] tested glass-ceramic butt joints between ferritic steel adherends in 4 point flexure. Their arrangement applies opening mode tensile stress to the joint rather than the shear applied in the 4-point loading of the present study. They report failure stresses in the range 43 to $52 \mathrm{MPa}$ for their joints in tensile bending, which are similar to the current results for the shear loading (38 $\mathrm{MPa}$, Table 2). It is clear that no single test gives a definitive value for the apparent strength of this type of brittle joint. (For example, a torsion test on a 
butt joint has been suggested as the best arrangement for applying a uniform pure shear [21,29].) Even under perfectly controlled loading of the joint, the strength can vary quite widely depending on the details of the test configuration. In addition, it is difficult to ensure perfect loading in the experimental arrangement due to misalignments in specimen fabrication and loading fixtures. Therefore great care must be taken in applying strength test data to engineering applications involving multi-axial loading of brittle joints of this type.

An issue that arises in strength testing of brittle materials is how to relate results on specimens of different size. In bulk ceramics this can be done by using the effective stressed volume (for initiation from volume defects) or the effective stressed area (for initiation from surface defects) which can be computed from the stress distribution. However, this is not considered here as it is not clear whether the strength-controlling defects are distributed in the volume, at the interface or at the edges of the joints.

Selection of a suitable test therefore depends on many factors and particularly on the intended purpose of the results. For example, the tests might be required to screen the mechanical performance of candidate materials or seal geometries. In such a case, the results will be of a semi-quantitative comparative nature and test selection will be dominated by ease of specimen fabrication and loading arrangements. The actual test selected will be of secondary importance provided that it is reliable, repeatable and its characteristics are understood. For example, in the present work the tests using the symmetric compression geometry show the triple layer joint has better performance than the single layer joint (Table 2) despite the fact that this test has been shown to give generally high apparent strength results because of the transverse compressive stresses. On the other hand, for assessing failure probability of seals in a stack, much more detailed analysis is required. The approach can be based on strength measurements, or on fracture mechanics, e.g. [30], or a combination of both. Whatever approach is taken, the fracture measurements must take into account the actual multi-axial loading in the stack as closely as possible.

\section{Conclusions}

The apparent shear strength of the joints varied dramatically with the test method used. In particular, the apparent shear strength measured in the asymmetric (offset) lap compression test was very low. This is due to small displacements in the lateral constraining mechanism (which ideally should be infinitely stiff) inducing significant tensile normal stresses 
perpendicular to the joint, which initiate failure. A strong correlation was found between the applied load at failure and the displacement of the restraint, even though the displacement was small (less than $10 \mu \mathrm{m}$ ).

Conversely, the highest apparent shear strengths were measured using the symmetric compression test in which significant transverse compressive stresses are maintained. The four-point asymmetric bend shear test gave an intermediate result and was least affected by transverse stresses, which are low in this configuration.

The demonstrated sensitivity of fracture to the transverse normal stresses shows that the presence of such stresses in a real component must be carefully considered before selecting the most appropriate test configuration.

The Weibull modulus was low and essentially independent of the test method. This indicates a similarly broad spectrum of defects that initiated failure, irrespective of whether the failure originated at the edge of the joint (asymmetric compression test) or at the interface away from the edge of the joint (four-point asymmetric bending).

The locus of failure was always along the glass/metal interface. However, in the symmetric compression test the crack deviated from the first interface approximately half way along the joint and crossed to the opposite interface as expected from the stress distribution. The crack deviation angle was measured to be $15^{\circ}$ for single layer joints and $18^{\circ}$ for triple layer joints.

\section{References}

1 J.W. Fergus, J. Power Sources 2005, 147, 46.

2 S. Ohara, K. Mukai, T. Fukui, Y. Sakaki, M. Hattori and Y. Esaki, J. Ceram. Soc. Japan, 2001, 109, 186.

3 R.S.T. Schwickert, P. Geasee and R. Conradt, Materialwissenschaft und Werkstofftechnik 2002, 33, 363.

4 Z.G. Yang, K.D. Meinhardt and J.W. Stevenson, J. Electrochem. Soc., 2003, 150, A1095. 
5 M. Bram, S. Reckers, P. Drinovac, J. Monch, R.W. Steinbrech, H.P. Buchkremer and D. Stover, J. Power Sources, 2004, 138, 111.

6 S.-B. Sohn, S.-Y. Choi, G.-H. Kim, H.-S. Song and G.-D. Kim, J. Amer. Ceram. Soc., 2004, 87, 254.

$7 \quad$ N.P. Bansal and E.A. Gamble, J. Power Sources, 2005, 147, 107.

8 N.H. Menzler, D. Sebold, M. Zahid, S.M. Gross and T. Koppitz, J. Power Sources, 2005, 152, 156.

9 P. Batfalsky, V.A.C. Haanappel, J. Malzbender, N.H. Menzler, V. Shemet, I.C. Vinke and R.W. Steinbrech, J. Power Sources, 2006, 155, 128.

10 S. Ghosh, P. Kundu, A. Das Sharma, R.N. Basu and H.S. Maiti, J. European Ceram. Soc., 2008, 28, 69 .

11 J. Malzbender, R.W. Steinbrech and L. Singheiser, J. Mat. Res., 2003, 18, 929.

12 J. Malzbender, J. Monch, R.W. Steinbrech, T. Koppitz, S.M. Gross and J. Remmel, J. Mat. Sci., 2007, 42, 6297.

13 B. Cela Greven, S.M. Gross-Barsnick, D. Federmann and R. Conradt, Fuel Cells, 2013, 13, 565 .

14 C.-K. Lin, Y.-A. Liu, S.-H. Wu, C.-K. Liu and R.-Y. Lee, J. Power Sources, 2015, $280,272$.

15 L. Blum, S.M. Gross, J. Malzbender, U. Pabst, M. Peksen, R. Peters, and I.C. Vinke, J. Power Sources, 2011, 196, 7175.

16 A. Atkinson and R. Guppy, Mat. Sci. Technol., 1991, 7, 1031.

17 P.Y. Hou and A. Atkinson, Materials at High Temperatures, 1994, 12, 119.

18 D. Korn, G. Elssner, H.F. Fischmeister and M. Ruhle, Acta Metall. Mater., 1992, 40, 335.

$19 \quad$ ASTM standard D 1002-72. 
20 A. Ventrella, M. Salvo, M. Avalle and M. Ferraris, J. Mat. Sci., 2010, 45, 4401.

21 M. Ferraris, A. Ventrella, M. Salvo, M. Avalle, F. Pavia and E. Martin, Composites Part B: Engineering, 2010, 41, 182.

22 D. Amara, F. Levallois, Y. Baziard and J.A. Petit, J. Adhesion Sci. Technol., 1996, 10, 1153.

23 ASTM standard D 3931-80.

24 A. Müller, S. Goswami, W. Becker, D. Stolten, L.G.J. de Haart and R.W. Steinbrech, Fuel Cells, 2006, 6, 107.

25 Ö. Ünal, I.E. Anderson and S.I. Maghsoodi, J. Amer. Ceram. Soc., 1997, 80, 1281.

26 S.M. Pickard, H. Zhang and A.K. Ghosh, Acta materialia, 1997, 45, 4333.

27 A.G. Evans, B.J. Dalgleish, M. He and J.W. Hutchinson, Acta Metallurgica, 1989, 37, 3249.

28 J. Malzbender and Y. Zhao, Fuel Cells, 2012, 12, 47.

29 J. Wei, G. Pećanac and J. Malzbender, Ceramics International, 2014, 40, 15371.

30 C.-K. Lin, W.-H. Shiu, S.-H. Wu, C.-K. Liu and R.-Y. Lee, J. Power Sources, 2014, $261,227$. 


\section{Tables}

Table $1 \quad$ Material parameters used in FEM analysis

\begin{tabular}{|l|c|c|c|}
\hline Parameter & Alloy $^{\mathrm{a}}$ & Glass $^{\mathrm{b}}$ & Spinel $^{\mathrm{c}}$ \\
\hline CTE $(\mathrm{ppm} / \mathrm{K})$ & 10.0 & 5.3 & 9.0 \\
\hline Young's modulus $(\mathrm{GPa})$ & 211 & 66 & 270 \\
\hline Poisson's ratio & 0.24 & 0.235 & 0.3 \\
\hline
\end{tabular}

a http://www.plansee.com/en/CFY-1484.htm

b http://www.matweb.com/

c http://www.ceramics.nist.gov/srd/summary/MgAl2O4.htm

Table 2 Summary of measured apparent shear strength of joints from different test configurations

\begin{tabular}{|c|c|c|c|c|}
\hline Bond type & Test configuration & $\begin{array}{c}\text { Mean apparent } \\
\text { shear strength } \\
\text { (MPa) } \pm \text { standard } \\
\text { deviation }\end{array}$ & $\begin{array}{c}\text { Weibull } \\
\text { modulus }\end{array}$ & $\begin{array}{c}\text { Characteristic } \\
\text { strength } \\
\text { (MPa) }\end{array}$ \\
\hline Triple layer & $\begin{array}{c}\text { Asymmetric } \\
\text { compression }\end{array}$ & $7.3 \pm 1.7$ & 5.3 & 7.9 \\
\hline Triple layer & $\begin{array}{c}\text { Symmetric } \\
\text { compression }\end{array}$ & $83 \pm 16$ & 6.4 & 73 \\
\hline Single layer & $\begin{array}{c}\text { Symmetric } \\
\text { compression }\end{array}$ & $66 \pm 17$ & 4.4 & 42 \\
\hline Single layer & $\begin{array}{c}\text { Four-point } \\
\text { asymmetric bend }\end{array}$ & $38 \pm 9$ & 4.0 & 90 \\
\hline
\end{tabular}




\section{Figure Captions}

Figure 1 Schematic diagrams of the three test configurations after optimisation using FEM: a) asymmetric compressive lap joint; b) symmetric compressive lap joint; and c) 4-point shear-loaded butt joint where $a=42 \mathrm{~mm}$ and $b=1 \mathrm{~mm}$ are the constants in Equation (1). Dimensions are given in $\mathrm{mm}$.

Figure 2 Stress distribution calculated by FEM along the centre line of the asymmetric lap joint in the optimised configuration. The stresses are normalised with respect to the average shear stress and the length of the joint, $L$, is $5 \mathrm{~mm}$. The $x_{1}$ axis is across the joint and the $x_{2}$ axis is along the joint.

Figure 3 Stress distribution calculated by FEM along the centre line of the symmetric lap joint in the optimised configuration. The stresses are normalised with respect to the average shear stress and the length of the joint, $L$, is $14 \mathrm{~mm}$. The $x_{1}$ axis is across the joint and the $x_{2}$ axis is along the joint.

Figure 4 Scanning electron micrograph of the edge of a typical joint.

Figure 5 Loading arrangement for the asymmetric lap joint compression test.

Figure 6 Loading arrangement for the symmetric lap joint compression test.

Figure 7 Loading arrangement for the four-point shear-loaded butt joint.

Figure 8 Weibull plot of the apparent shear strength of triple layer bonded joints tested in the asymmetric and symmetric compression tests. 
Figure 9 Apparent shear strength of triple layer bonded joints tested in the asymmetric compression test as a function of the lateral displacement of the upper restraint.

Figure 10 FEM simulation of stresses across a 3-layer joint in the asymmetric lap joint test configuration at an applied load of $1000 \mathrm{~N}$ assuming the upper restraint has deflected by $10 \mu \mathrm{m}$. The location of the section is $60 \mathrm{~mm}$ below the top edge of the joint and the compressive load is applied to the metal on the left.

Figure 11 Weibull plot of the apparent shear strength of single layer bonded joints tested in the symmetric compression and 4-point asymmetric bending tests.

Figure 12 Surface profiles of the fracture path measured after the symmetric compression test on (a) triple layer and (b) single layer joints. The crack deviation angle is indicated. 

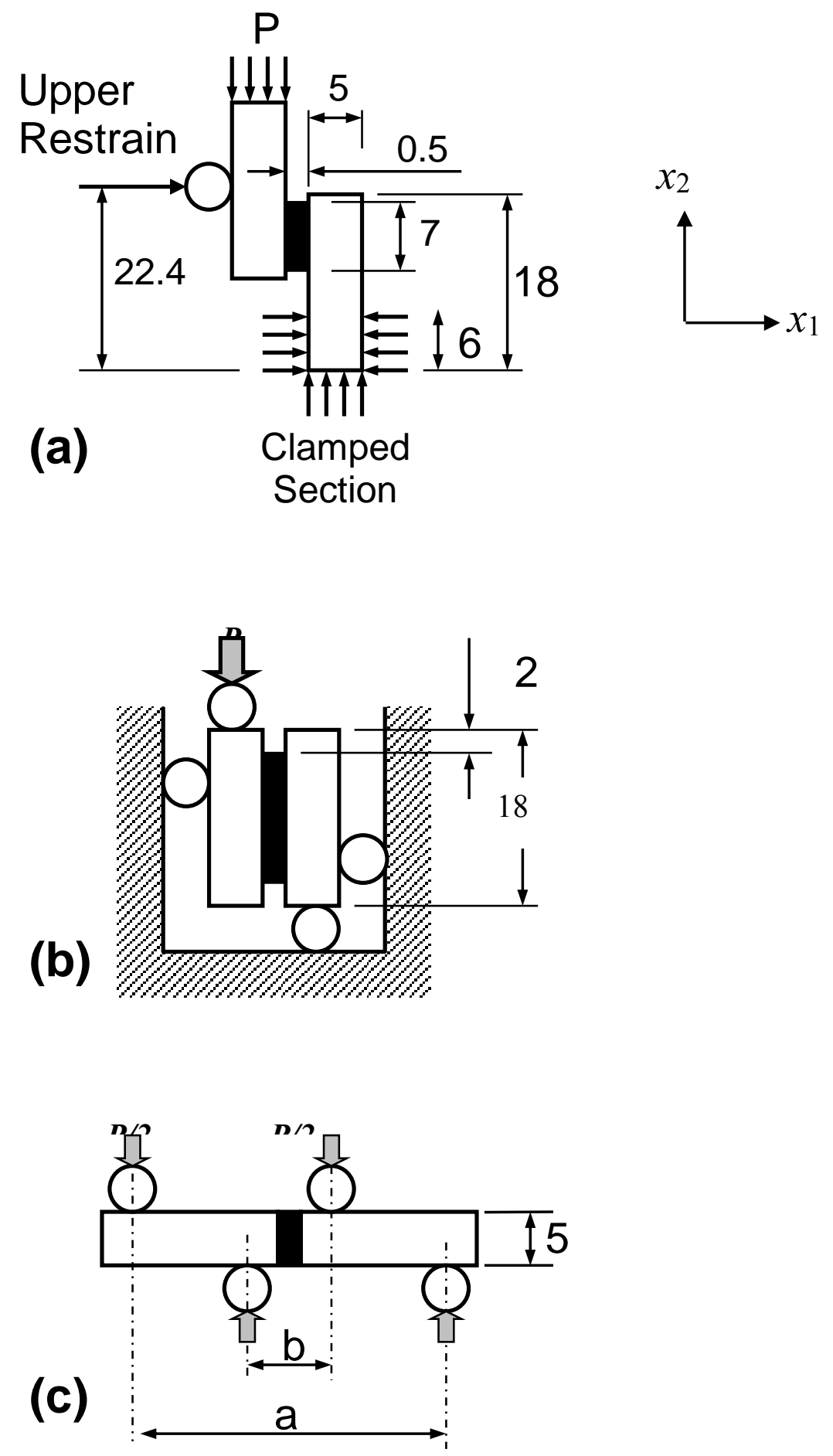

Figure 1 Schematic diagrams of the three test configurations after optimisation using FEM: a) asymmetric compressive lap joint; b) symmetric compressive lap joint; and c) 4-point shear-loaded butt joint where $a=42 \mathrm{~mm}$ and $b=1 \mathrm{~mm}$ are the constants in Equation (1). Dimensions are given in $\mathrm{mm}$. 


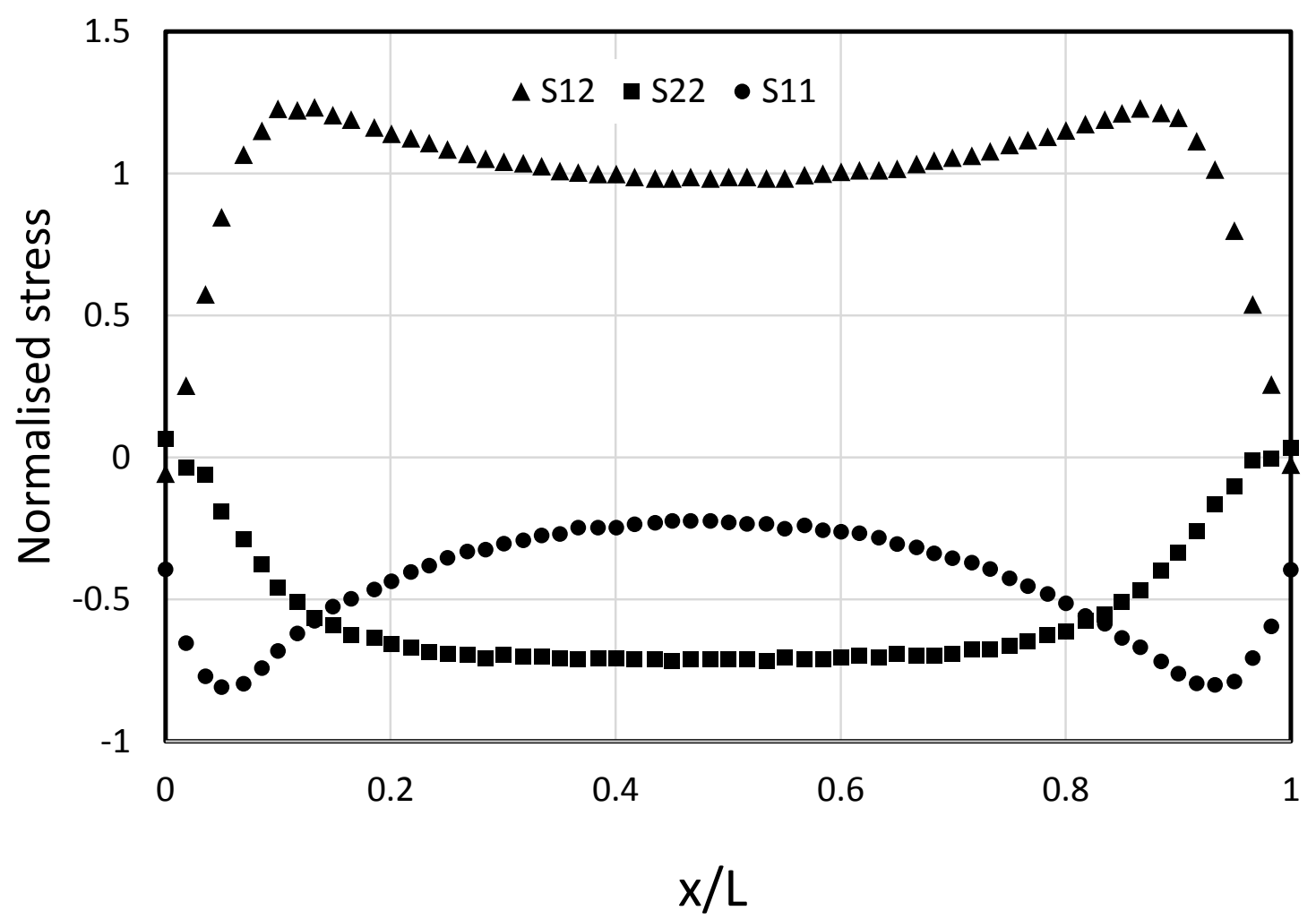

Figure 2 Stress distribution calculated by FEM along the centre line of the asymmetric lap joint in the optimised configuration. The stresses are normalised with respect to the average shear stress and the length of the joint, $L$, is $5 \mathrm{~mm}$. The $x_{1}$ axis is across the joint and the $x_{2}$ axis is along the joint. 


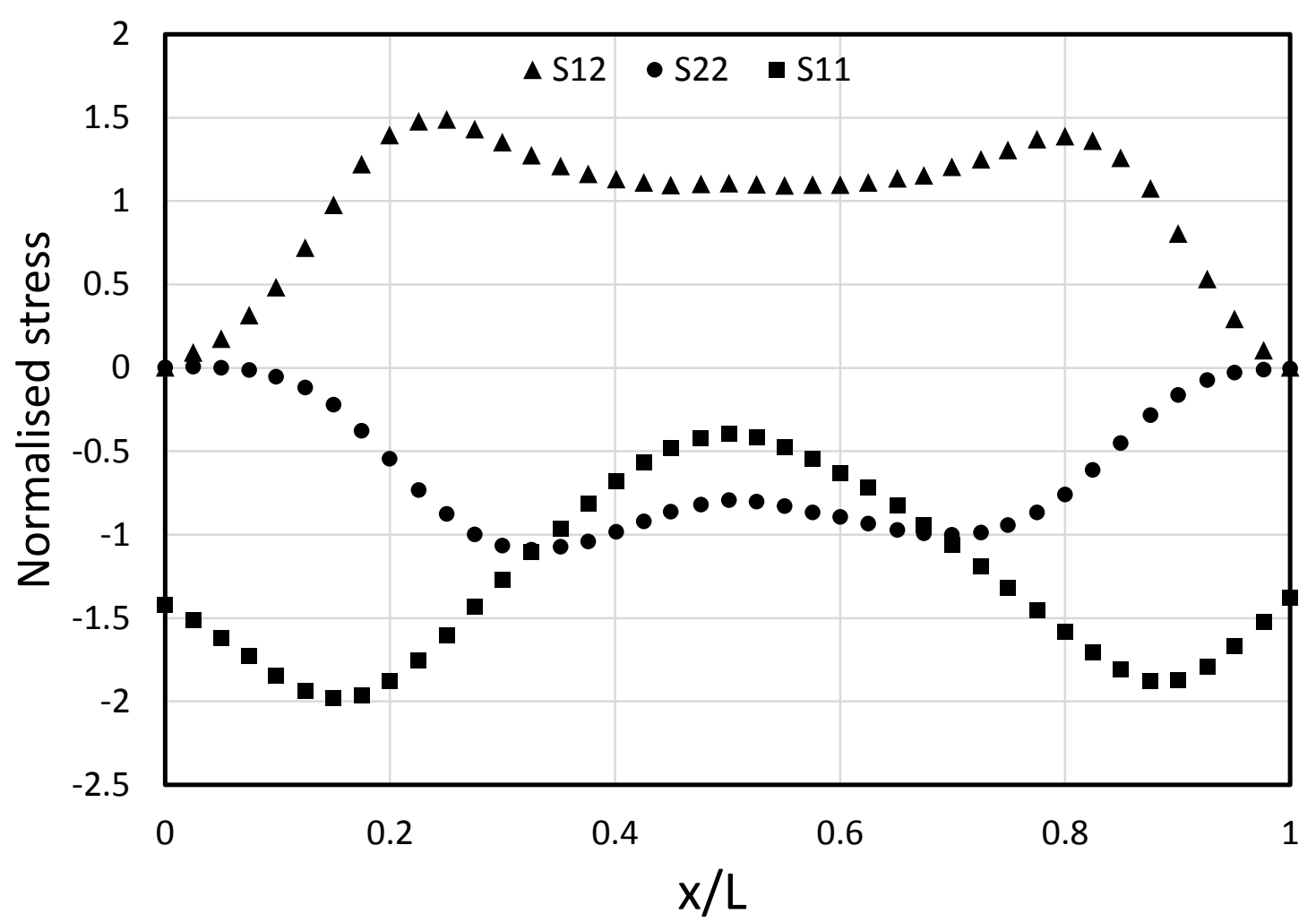

Figure 3 Stress distribution calculated by FEM along the centre line of the symmetric lap joint in the optimised configuration. The stresses are normalised with respect to the average shear stress and the length of the joint, $L$, is $14 \mathrm{~mm}$. The $x_{1}$ axis is across the joint and the $x_{2}$ axis is along the joint. 


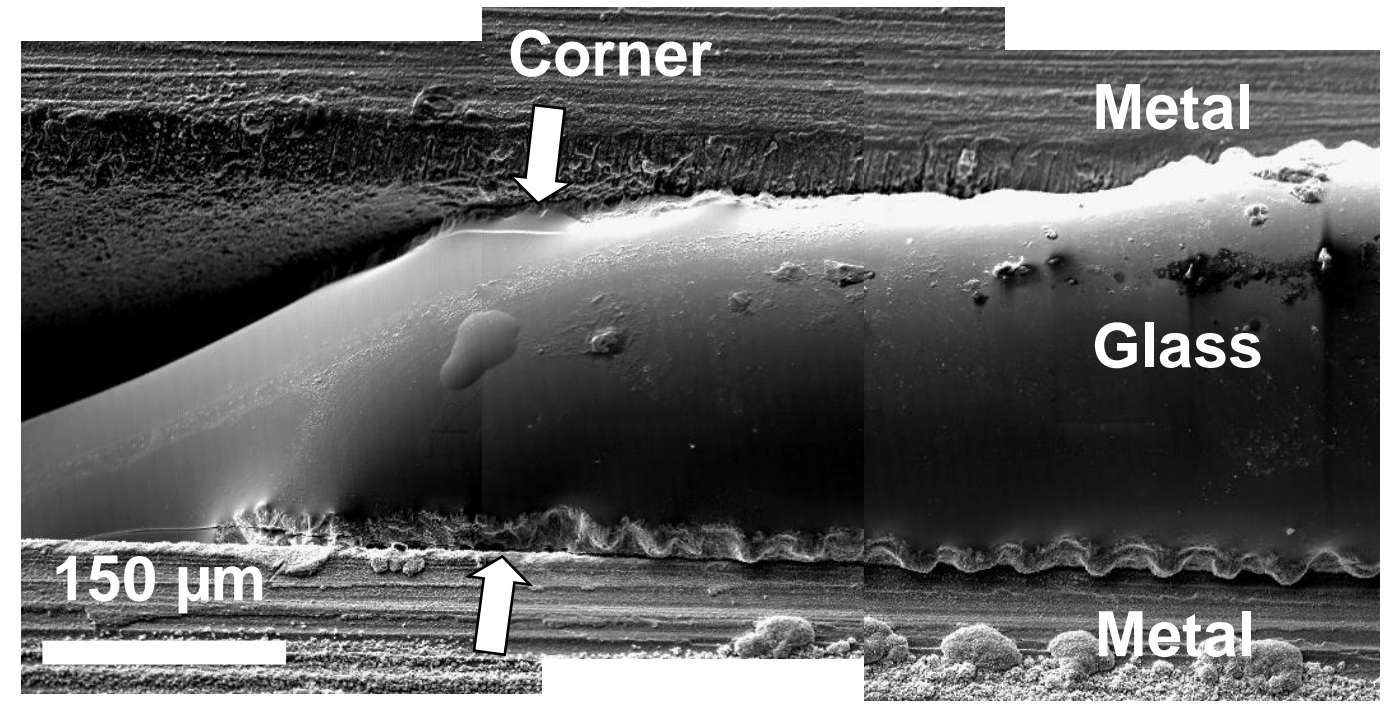

Figure 4 Scanning electron micrograph of the edge of a typical joint. 


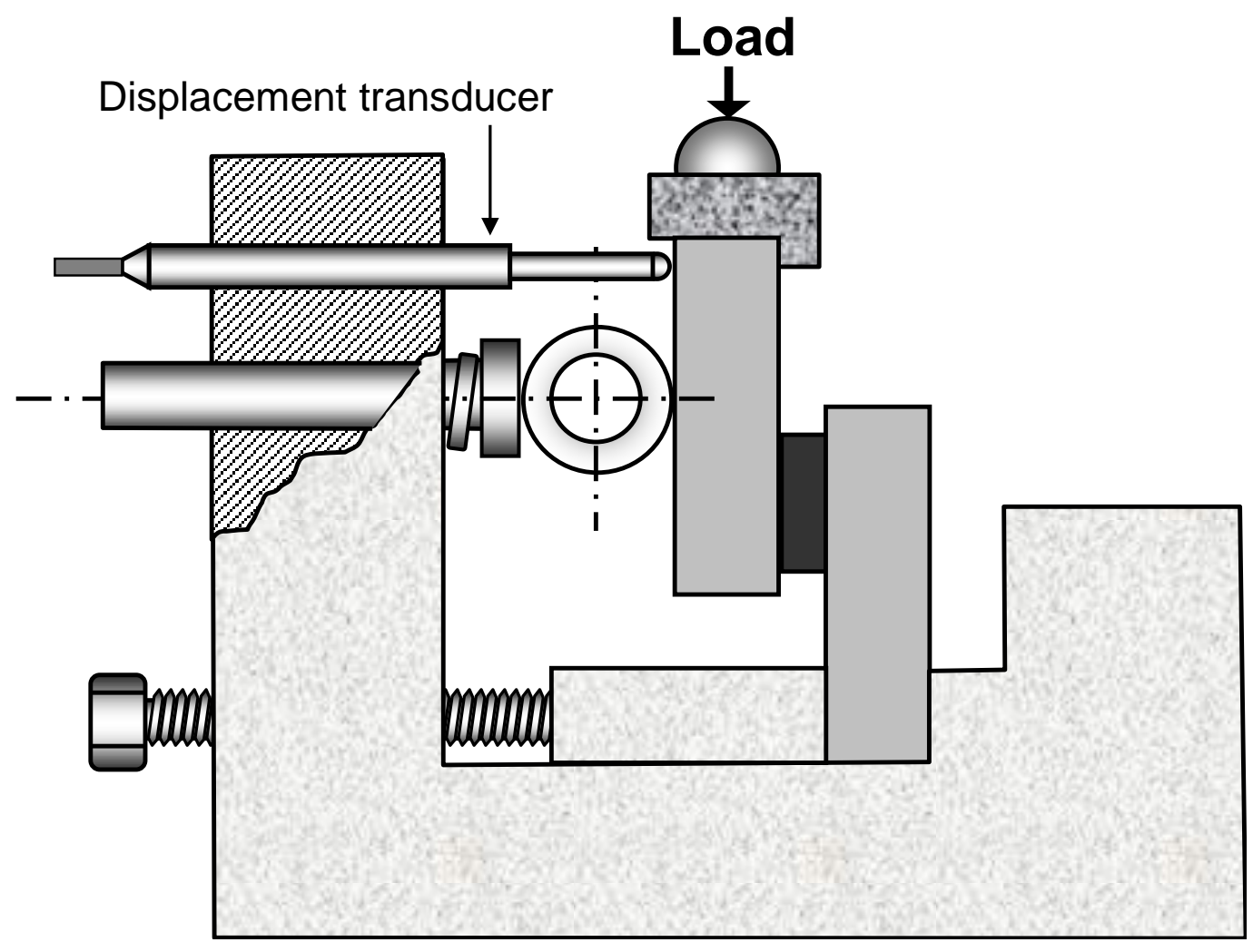

Figure 5 Loading arrangement for the asymmetric lap joint compression test. 


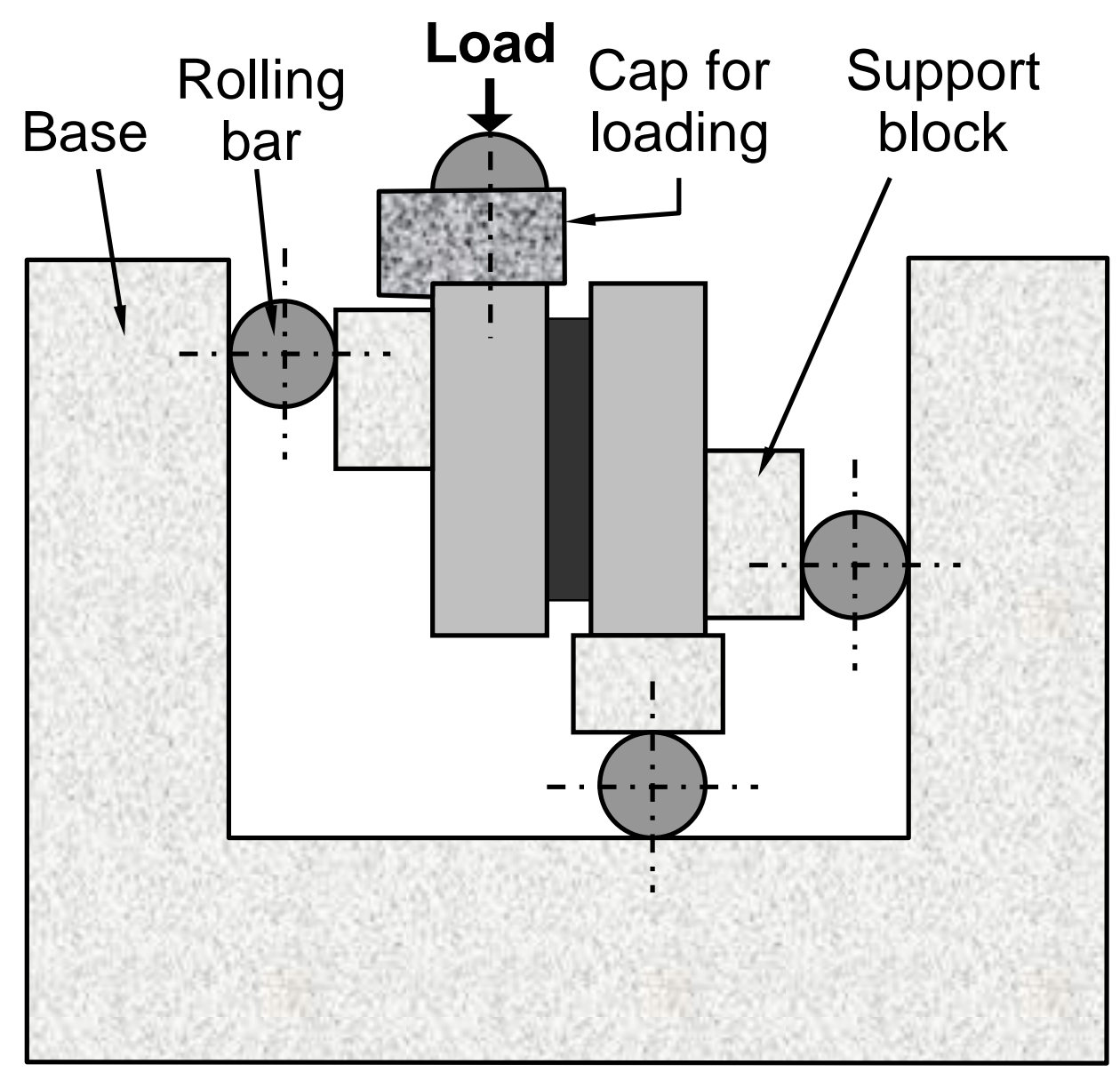

Figure 6 Loading arrangement for the symmetric lap joint compression test. 


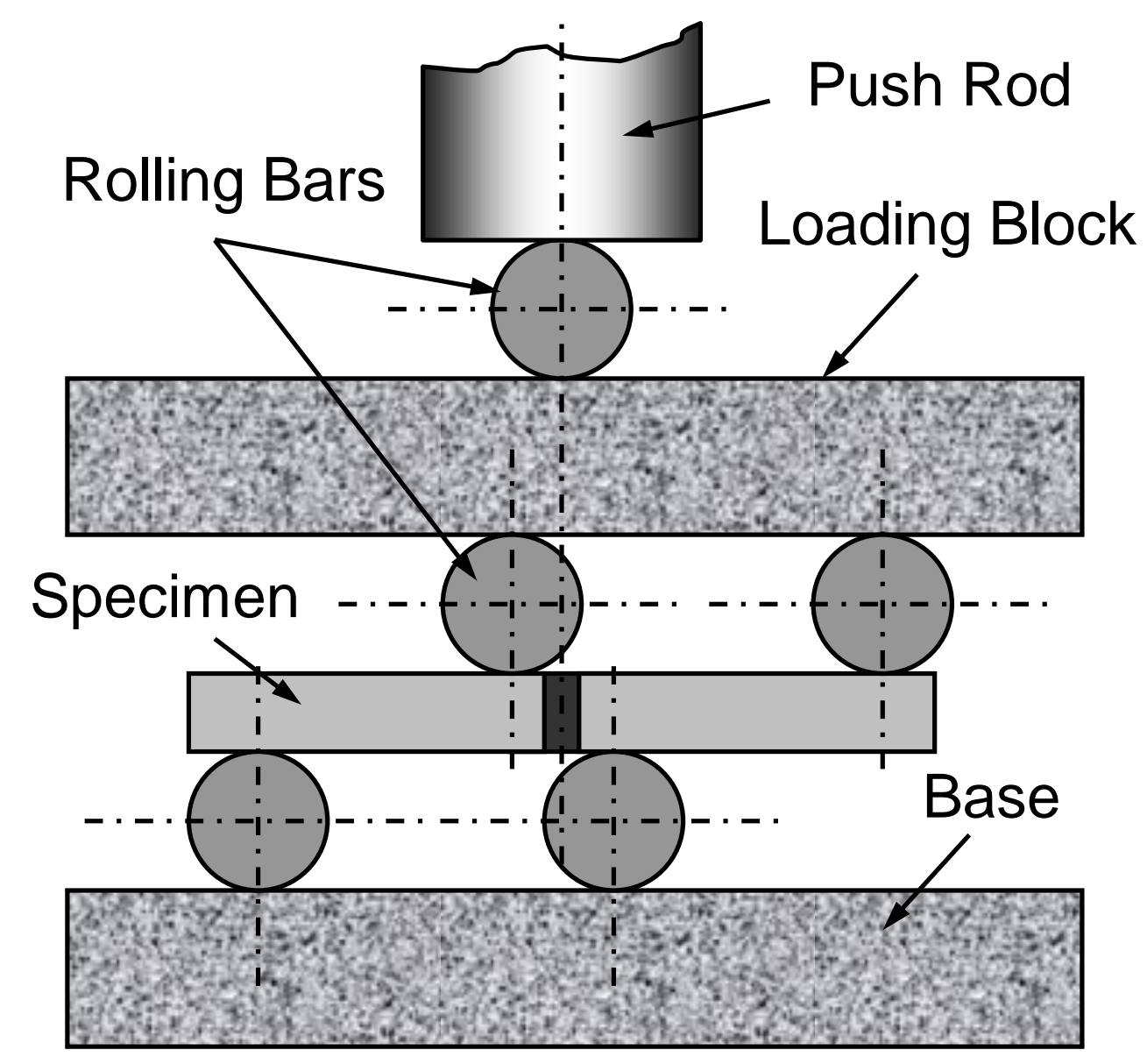

Figure 7 Loading arrangement for the four-point shear-loaded butt joint. 


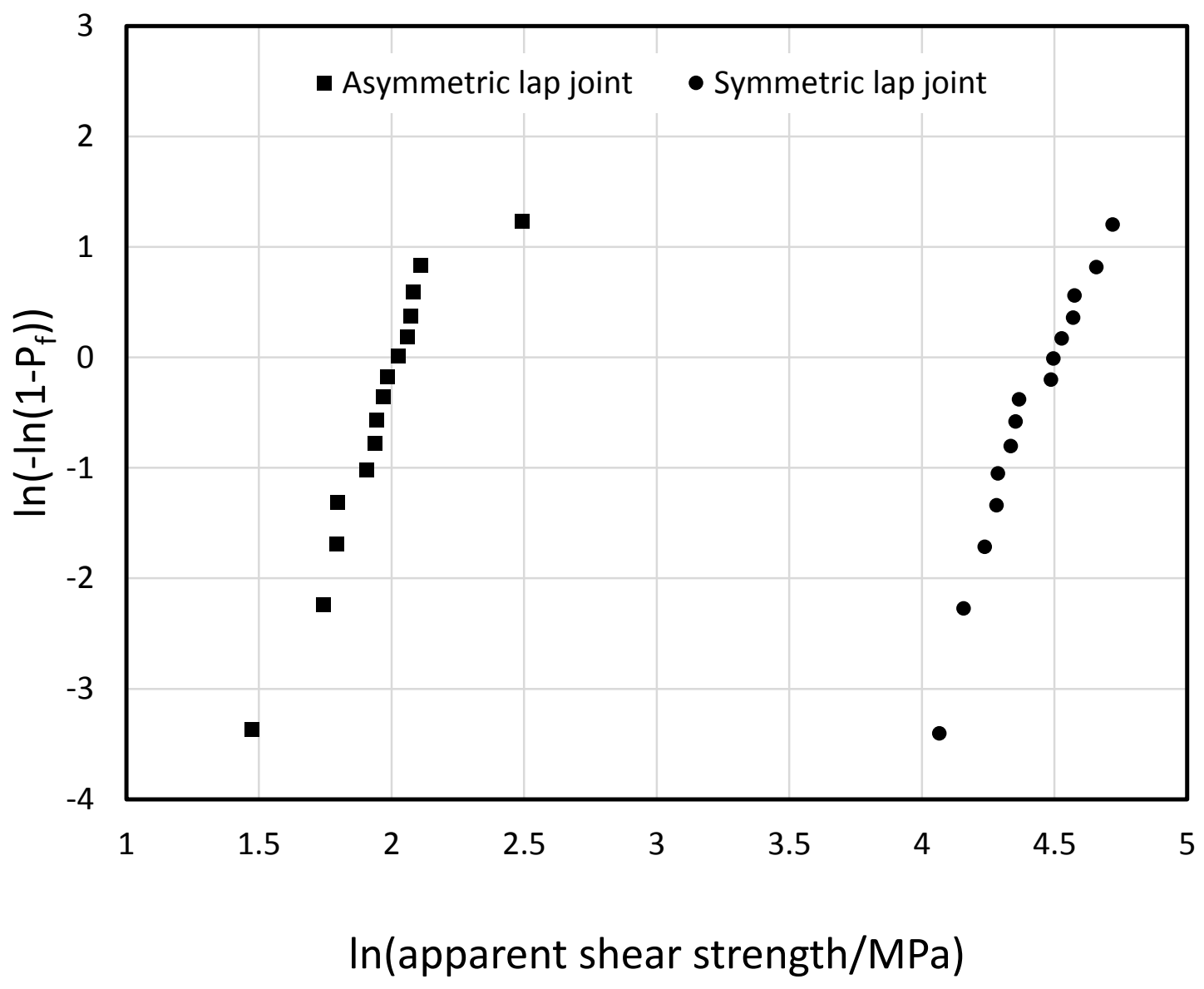

Figure 8 Weibull plot of the apparent shear strength of triple layer bonded joints tested in the asymmetric and symmetric compression tests. 


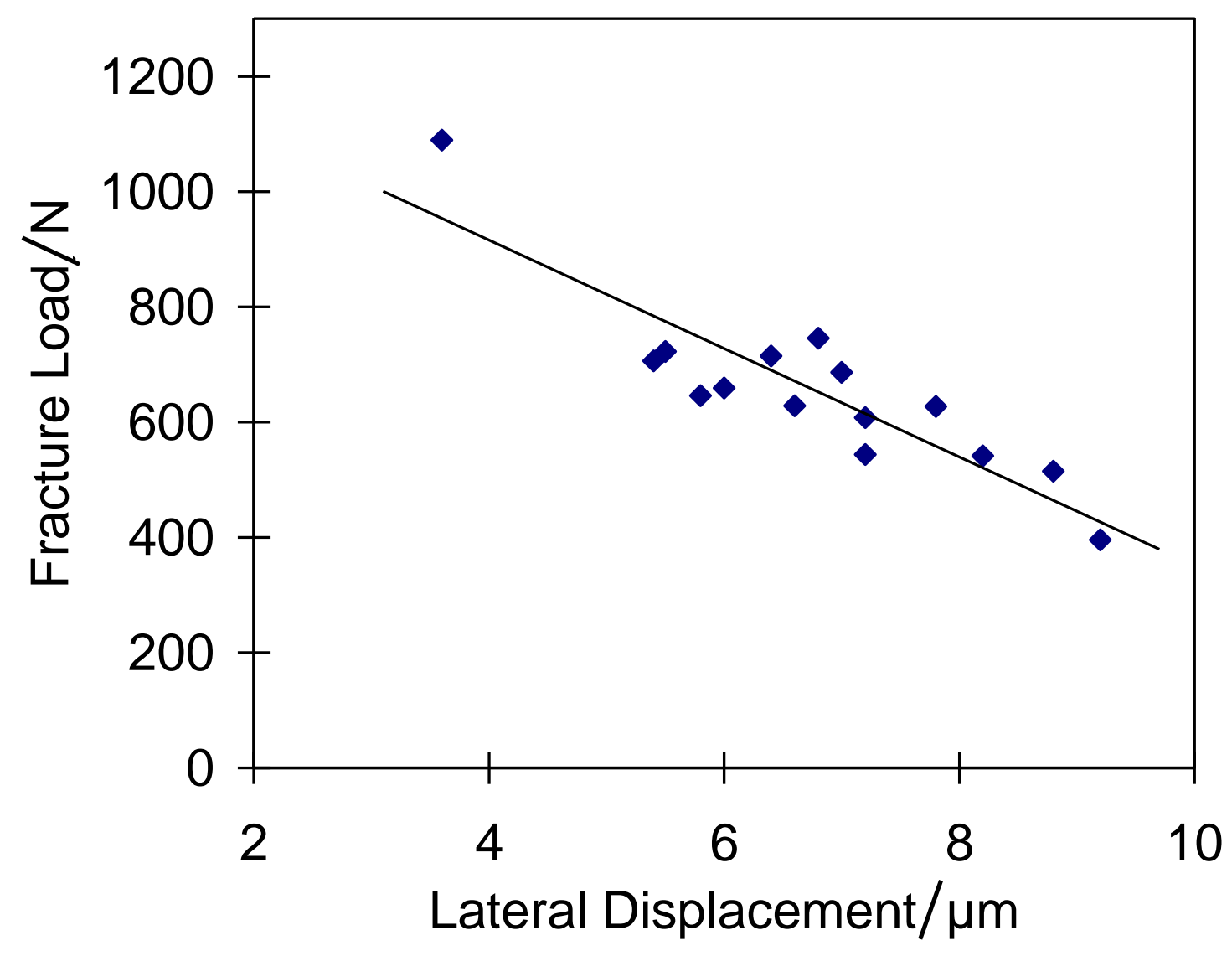

Figure 9 Apparent shear strength of triple layer bonded joints tested in the asymmetric compression test as a function of the lateral displacement of the upper restraint. 


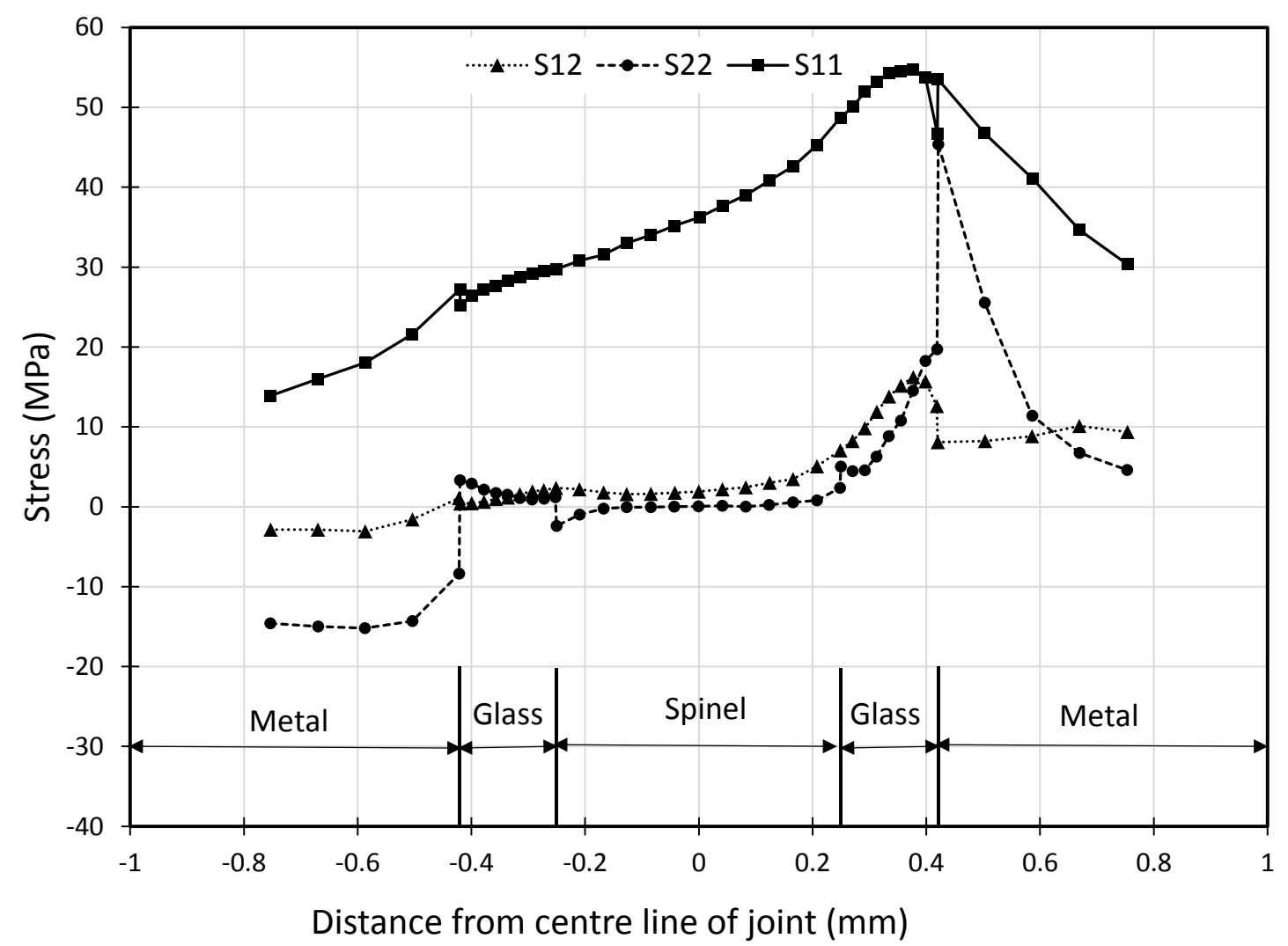

Figure 10 FEM simulation of stresses across a 3-layer joint in the asymmetric lap joint test configuration at an applied load of $1000 \mathrm{~N}$ assuming the upper restraint has deflected by $10 \mu \mathrm{m}$. The location of the section is $60 \mathrm{~mm}$ below the top edge of the joint and the compressive load is applied to the metal on the left. 


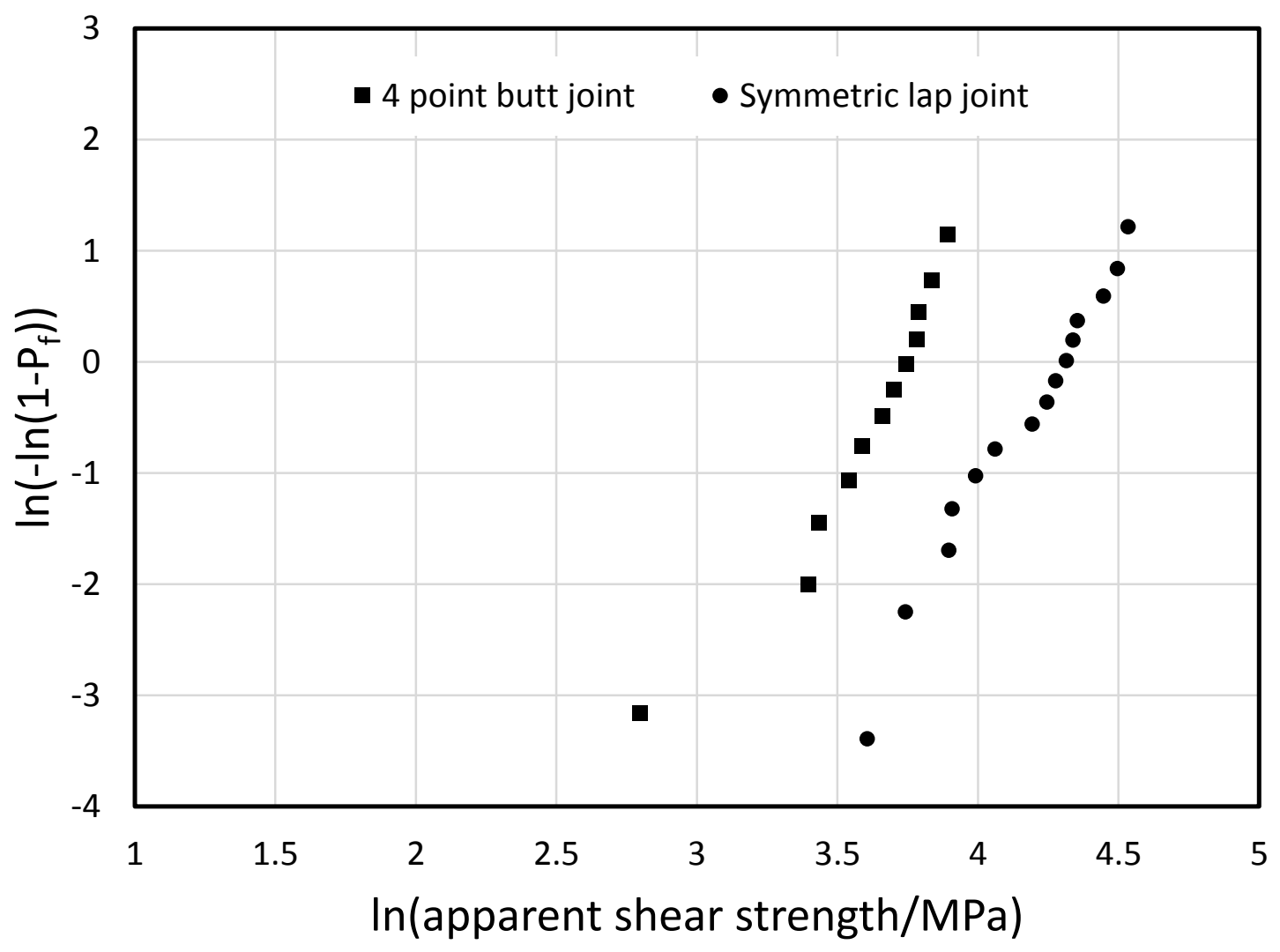

Figure 11 Weibull plot of the apparent shear strength of single layer bonded joints tested in the symmetric compression and 4-point asymmetric bending tests. 

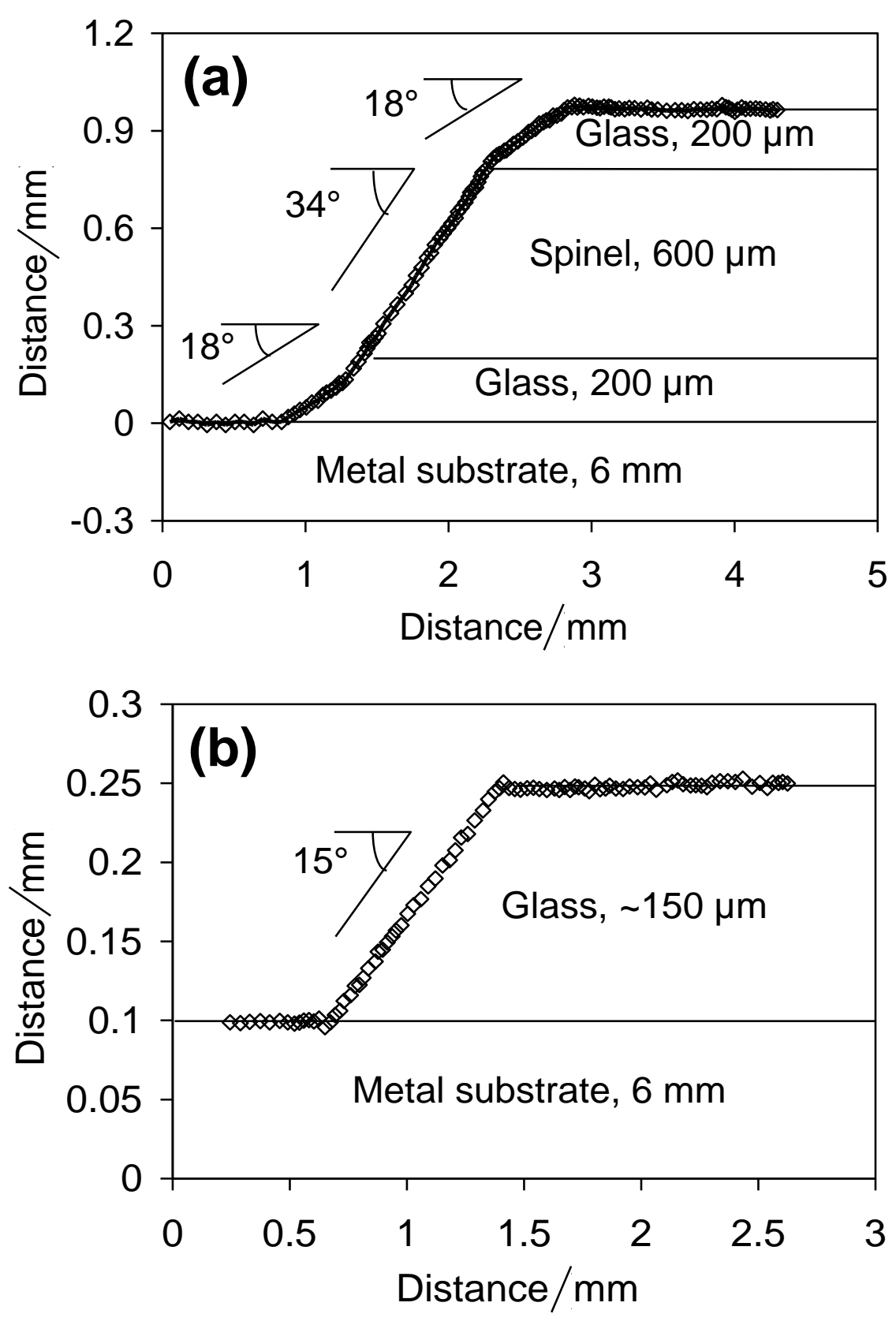

Figure 12 Surface profiles of the fracture path measured after the symmetric compression test on (a) triple layer and (b) single layer joints. The crack deviation angle is indicated. 